\title{
Association of blood glucose and lipid levels with complete blood count indices to establish a regression model
}

\author{
GUANGSHU HAO ${ }^{1}$, DAN WANG ${ }^{1}$, YANNI SUN ${ }^{1}$, JIONG YU ${ }^{2}$, FEIYAN LIN ${ }^{1}$ and HONGCUI CAO ${ }^{1,2}$ \\ ${ }^{1}$ Central Laboratory, The First Affiliated Hospital, Wenzhou Medical University, \\ Wenzhou, Zhejiang 325000; ${ }^{2}$ The State Key Laboratory for Diagnosis and Treatment of Infectious Diseases, \\ The First Affiliated Hospital, College of Medicine, Zhejiang University, Hangzhou, Zhejiang 310003, P.R. China
}

Received October 10, 2016; Accepted November 23, 2016

DOI: $10.3892 /$ br.2017.852

\begin{abstract}
Hyperglycemia and hyperlipidemia, which are usually diagnosed by analysis of blood glucose (GLU) and lipid levels, are two of the most common diseases in modern society. The purpose of the current study was to investigate the potential association between blood GLU and lipid levels with complete blood count (CBC) indices in overweight and healthy individuals and establish a regression model. There were 456 healthy and 421 overweight participants in the study. Data were collected on triglyceride (TG), total cholesterol (CHO), high-density lipoprotein cholesterol (HDL-C), low-density lipoprotein cholesterol (LDL-C), blood GLU and $\mathrm{CBC}$. The distribution characteristics and differences between healthy and overweight subjects were analyzed. Subsequently, the associations between TG, CHO, HDL, LDL and GLU with $\mathrm{CBC}$ were analyzed using correlation analysis and multiple linear regression (MLR). Significant differences were identified between the healthy and overweight individuals in TG, $\mathrm{CHO}, \mathrm{HDL}, \mathrm{LDL}, \mathrm{GLU}$ and in the majority of the CBC indices. The correlation analysis indicated that there were strong correlations between TG, LDL, HDL, CHO and GLU with $\mathrm{CBC}$ indices in the healthy and overweight subjects. The MLR demonstrated that the regression models of TG, LDL, HDL and CHO, but no GLU, were statistically significant in the two groups $(\mathrm{P}<0.001)$. The HDL regression model exhibited the best regression parameters; the multiple correlation coefficients (R) were 0.351 and 0.308 in the healthy and overweight subjects, respectively. In the overweight and healthy subjects, there were strong correlations between TG, LDL,
\end{abstract}

Correspondence to: Dr Hongcui Cao, The State Key Laboratory for Diagnosis and Treatment of Infectious Diseases, The First Affiliated Hospital, College of Medicine, Zhejiang University, Building 6A, 79 QingChun Road, Hangzhou, Zhejiang 310003, P.R. China

E-mail: hccao@zju.edu.cn

Key words: blood glucose, blood lipid, complete blood count, overweight
HDL and $\mathrm{CHO}$ with $\mathrm{CBC}$ indices, with HDL being the most relevant to the $\mathrm{CBC}$ indices. The $\mathrm{CBC}$ demonstrated statistical significance in the diagnosis of hyperlipidemia.

\section{Introduction}

Hyperglycemia and hyperlipidemia, characterized by elevated blood glucose (GLU) and lipid levels, are two of the most common public health issues worldwide in modern society (1). Hyperglycemia is the main symptom of type I and type II diabetes, and the incidence of diabetes has been rapidly increasing in recent years worldwide. It has been estimated that there was 382 million people with type II diabetes mellitus in 2013, while the prevalence of diabetes is estimated to increase by $55 \%$ in 2035 , reaching a total number of 592 million (1). Dyslipidemia, which is defined by elevated total cholesterol (CHO), triglyceride (TG) and/or low-density lipoprotein cholesterol (LDL-C) levels, and non-optimal levels of high-density lipoprotein cholesterol (HDL-C), is particularly prevalent worldwide (2-4).

Persistent hyperglycemia and hyperlipidemia damages the eyes, kidneys, feet and heart and causes a series of cardiovascular diseases, such as stroke, coronary heart disease and peripheral arterial disease (5-8). According to an estimated 4 million mortalities each year, dyslipidemia is considered to be a major modifiable risk factor for cardiovascular disease worldwide (9). Therefore, hyperglycemia and hyperlipidemia have presented a serious social problem.

The examination of blood GLU and lipid levels is routinely performed for early diagnosis of hyperglycemia and hyperlipidemia. When compared with healthy weight individuals, overweight individuals exhibit a greater risk for hyperglycemia, hyperlipidemia, and other diseases, such as high blood pressure, diabetes mellitus and coronary heart disease (10-12). Thus, monitoring blood GLU and lipid levels is popular and necessary, particularly in overweight individuals.

Blood routine examination also termed complete blood count (CBC) is an analysis of three major types of cells: Red blood cells (RBCs), white blood cells (WBCs) and platelets. It is a common blood test used in clinical and routine health examinations, which is beneficial for early diagnoses of serial diseases, such as anemia and infections. Furthermore, there are benefits of identifying the association between these indices, 
not only experienced by overweight people, but also in healthy individuals (13). However, there are critical knowledge gaps on the correlation of blood GLU and lipid levels with CBC test results. In the current study, the association between these indices in healthy and overweight individuals was investigated.

\section{Materials and methods}

Subjects and ethics. Individuals with a history of disease, such as hematopathy, angiocardiopathy, hepatopathy, nephrosis or pulmonary disease were not recruited for the present study. A total of 877 subjects were recruited between September and December 2015, comprising 456 healthy subjects (147 male and 308 female) and 421 overweight subjects (305 male and 116 female), with mean ages of $39.70 \pm 10.89$ and $45.74 \pm 11.19$ years, respectively. Their heights and weights were measured using a stadiometer and electronic weighing scale, respectively. Body mass index (BMI) was then calculated as follows: $\mathrm{BMI}=$ weight $/ \mathrm{height}^{2}$ to divide the subjects into the healthy $\left(\mathrm{BMI}=18-25.0 \mathrm{~kg} / \mathrm{m}^{2}\right)$ and overweight $\left(\mathrm{BMI}=25.0-30 \mathrm{~kg} / \mathrm{m}^{2}\right)$ groups according to the criterion recommended by the World Health Organization (14). The data (anonymous) for this study was provided by the First Affiliated Hospital of Wenzhou Medical University (Wenzhou, China). The study was approved by the hospital ethics committee and conducted in accordance with the Declaration of Helsinki. All participants provided informed consent for the analysis of their clinical data.

Blood examination. To determine the blood GLU and lipid levels, a total of $3 \mathrm{ml}$ fasting venous blood was collected from the subjects into separation gel tubes and separated at $3,466 \times \mathrm{g}$ for $10 \mathrm{~min}$. The plasma was analyzed in a Hitachi 705/717 biochemical instrument (Hitachi, Ltd., Tokyo, Japan) at $20^{\circ} \mathrm{C}$. The fasting blood GLU, TG, CHO, HDL and LDL levels were then determined (Table I). To establish the CBC indices, $2 \mathrm{ml}$ venous blood was collected into heparinized tubes and determined using a BC-5500 Automatic Blood Cell Analyzer (Mindray Bio-Medical Electronics Co., Ltd., Shenzhen, China). A total of 18 CBC indices were included in the current study; their detailed descriptions are presented in Table I.

Statistical analysis. Prior to correlation analysis, the distribution characteristics of the blood indices data were analyzed using the Shapiro-Wilk and homogeneity of variances tests. The differences between healthy and overweight subjects were analyzed by nonparametric test when the indices were abnormally distributed, and the correlations between TG, CHO HDL, LDL and GLU, and CBC indices were analyzed by bivariate correlation.

When a correlation between blood GLU and lipid levels and $\mathrm{CBC}$ indices was identified, multiple linear regression (MLR) analysis was then conducted using a stepwise method. All CBC indices were subjected to MLR analyses to identify the relationship between TG, CHO and GLU. One-way ANOVA was used to analyze the difference and $\mathrm{P}<0.05$ was considered to indicate a statistically significant difference. The correlation of the regression residual was determined by the Durbin-Watson value. All statistical analyses were conducted using SPSS software (version 17.0; SPSS, Inc., Chicago, IL, USA).

\section{Results}

Characteristics of healthy and overweight individuals. A total of 456 healthy subjects ( 147 male and 308 female) and 421 overweight subjects ( 305 male and 116 female) were included in the current study (mean age, $39.70 \pm 10.89$ and $45.74 \pm 11.19$ years, respectively). The BMIs were $19.66 \pm 5.59$ and $26.39 \pm 1.92$ for the healthy and overweight groups, respectively. As the results of the Shapiro-Wilk test showed that the indices were abnormally distributed in the two different groups, the blood GLU, blood lipid and CBC indices data from the two groups were analyzed using a nonparametric test. The variance analysis indicated that there were significant differences between the healthy and overweight subjects; the TG, CHO, HDL, LDL, GLU and the majority of the CBC indices were altered. The level of TG, CHO, LDL, and GLU increased $(\mathrm{P}<0.01)$, while the HDL level decreased $(\mathrm{P}<0.01)$ in the overweight subjects (Table I).

Correlation analysis of glucose and lipid levels in healthy and overweight subjects. The results indicated that TG, LDL and HDL were strongly correlated with the $\mathrm{CBC}$ indices of the healthy subjects (Table II). There were 9 indices of CBC correlated with TG, 6 indices of $\mathrm{CBC}$ correlated with LDL, and 11 indices of $\mathrm{CBC}$ correlated with HDL. Compared with TG (the most important index for hyperlipidemia), GLU and $\mathrm{CHO}$ only demonstrated three and two relevant $\mathrm{CBC}$ indices, respectively.

This correlation almost did not change in the overweight subjects (Table III). There were 8 indices of CBC correlated with TG, 5 indices of CBC correlated with LDL, and 11 indices of $\mathrm{CBC}$ correlated with HDL. In addition, the relevant CBC indices in the overweight subjects were almost the same as in the healthy subjects. These findings indicated that the correlation of TG, HDL, LDL, CHO and GLU with the CBC indices did not change according to weight.

MLR analysis. According to the results of correlation analysis, there was strong correlation of TG, LDL, HDL, CHO and GLU with the $\mathrm{CBC}$ indices, and scatter diagrams demonstrated their linear correlation, which indicated that MLR could be used in the study. As there were various indices associated with each other, in order to evaluate independent CBC indices correlated with TG, LDL, HDL, CHO and GLU, MLR analysis was conducted using a stepwise method.

Regression models were generated for TG, LDL, HDL and CHO (Table IV), but not GLU, where no regression model was generated in the healthy subjects according to the stepwise method. The regression models of TG, LDL, HDL, and $\mathrm{CHO}$ all demonstrated statistical significance in the two groups $(\mathrm{P}<0.001)$. The regression models of healthy subjects exhibited greater multiple correlation coefficient (R), determinate coefficient $\left(R^{2}\right)$ and $F$ values when compared with the overweight subjects with regard to TG, LDL, HDL and CHO. These results indicated that the regression models of the healthy subjects were better than those for the overweight subjects. 
Table I. Characteristics and variance analysis of blood glucose, lipid and CBC indices in healthy $(\mathrm{n}=456)$ and overweight $(\mathrm{n}=421)$ subjects.

\begin{tabular}{|c|c|c|c|c|c|c|c|}
\hline \multirow[b]{2}{*}{ Blood index } & \multirow[b]{2}{*}{ Abbreviation } & \multirow[b]{2}{*}{ Unit } & \multicolumn{2}{|c|}{ Healthy } & \multicolumn{2}{|c|}{ Overweight } & \multirow[b]{2}{*}{ P-value } \\
\hline & & & Mean & SD & Mean & SD & \\
\hline Triglyceride & TG & $\mathrm{mmol} / \mathrm{l}$ & 0.97 & 0.41 & 1.99 & 1.60 & 0.000 \\
\hline Low-density Lipoprotein & LDL & $\mathrm{mmol} / \mathrm{l}$ & 2.48 & 0.57 & 2.88 & 0.70 & 0.000 \\
\hline High-density lipoprotein & HDL & $\mathrm{mmol} / \mathrm{l}$ & 1.51 & 0.30 & 1.27 & 0.29 & 0.000 \\
\hline Total cholesterol & $\mathrm{CHO}$ & $\mathrm{mmol} / \mathrm{l}$ & 4.48 & 0.66 & 4.96 & 0.88 & 0.000 \\
\hline Glucose & GLU & $\mathrm{mmol} / \mathrm{l}$ & 5.34 & 0.41 & 5.90 & 1.14 & 0.000 \\
\hline Percentage of monocyte & PMC & $\%$ & 0.07 & 0.02 & 0.07 & 0.02 & 0.573 \\
\hline Absolute value of monocyte & AVM & $\mathrm{x} 10^{9} / 1$ & 0.42 & 0.14 & 0.49 & 0.17 & 0.000 \\
\hline Red blood cell & $\mathrm{RBC}$ & $\mathrm{x} 10^{12} / 1$ & 4.66 & 0.47 & 4.98 & 0.47 & 0.000 \\
\hline Hematocrit & HCT & $1 / 1$ & 0.43 & 0.04 & 0.45 & 0.04 & 0.000 \\
\hline Percentage of leukomonocyte & PLC & $\%$ & 0.37 & 0.08 & 0.37 & 0.08 & 0.766 \\
\hline Absolute value of leukomonocyte & AVLC & $\mathrm{x} 10^{9} / 1$ & 2.13 & 0.60 & 2.41 & 0.66 & 0.000 \\
\hline Mean corpuscular volume & $\mathrm{MCV}$ & $\mathrm{fl}$ & 91.61 & 5.81 & 91.42 & 5.62 & 0.248 \\
\hline Mean corpuscular hemoglobin & $\mathrm{MCH}$ & pg & 29.79 & 2.32 & 30.20 & 2.30 & 0.001 \\
\hline Mean corpuscular hemoglobin concentration & $\mathrm{MCHC}$ & $\mathrm{g} / \mathrm{l}$ & 324.89 & 10.04 & 330.06 & 11.19 & 0.000 \\
\hline Mean platelet volume & MPL & $\mathrm{fl}$ & 10.83 & 1.80 & 10.93 & 1.57 & 0.394 \\
\hline Absolute value of eosinophils & AVE & $\mathrm{x} 10^{9} / 1$ & 0.13 & 0.10 & 0.17 & 0.12 & 0.000 \\
\hline Percentage of eosinophils & PE & $\%$ & 0.02 & 0.02 & 0.02 & 0.02 & 0.023 \\
\hline Hemoglobin & HB & $\mathrm{g} / \mathrm{l}$ & 138.34 & 14.70 & 149.95 & 15.47 & 0.000 \\
\hline Blood platelet & PLT & $\mathrm{x} 10^{9} / 1$ & 221.56 & 48.89 & 224.31 & 51.35 & 0.748 \\
\hline Thrombocytocrit & THR & $1 / 1$ & 0.24 & 0.06 & 0.24 & 0.06 & 0.261 \\
\hline Percentage of neutrophils & $\mathrm{PN}$ & $\%$ & 0.53 & 0.08 & 0.54 & 0.08 & 0.969 \\
\hline Absolute value of neutrophils & AVN & $\mathrm{x} 10^{9} / 1$ & 3.16 & 1.03 & 3.62 & 1.23 & 0.000 \\
\hline Red blood cell volume distribution width & RBCVD & $\%$ & 12.81 & 0.94 & 12.79 & 0.92 & 0.642 \\
\hline
\end{tabular}

CBC, complete blood count; SD, standard deviation.

In these four types of regression model, the multiple Rs of the HDL regression model were 0.351 and 0.308 in the healthy and overweight subjects, respectively, which were greater than those of the TG, LDL and CHO regression models. In addition, the $\mathrm{R}^{2}$ and $\mathrm{F}$ values of HDL regression model were higher than TG, LDL and CHO regression models, and the regression standardized residual demonstrated a normal distribution (Fig. 1). However, the R of TG was 0.319 in the healthy subjects, and was decreased to 0.189 in the overweight subjects, and the regression standardized residual was similar to a skewed normal distribution (Fig. 2). Therefore, HDL was identified as the most suitable index for linear regression when $\mathrm{CBC}$ indices were selected as independent variables.

\section{Discussion}

$\mathrm{CBC}$ is the most ubiquitous diagnostic parameter in the clinical setting, and is routinely analyzed to evaluate the health of patients (15). Generally, the CBC test provides important information regarding three major types of cells in the blood, RBCs, WBCs and platelets. Other indices, such as absolute value of monocyte, hematocrit, absolute value of leukomonocyte, mean corpuscular hemoglobin concentration, hemoglobin, PLC and thrombocytocrit, are all obtained from these three types of cell. These measurements are usually performed to test for blood disease, infection and many other disorders, which are associated with RBCs, WBCs and platelets. For example, inflammation, leukemia, bone marrow failure and immunodeficiency are diagnosed by irregular WBC counts and their differentials (16).

In the current study, the association of CBC with blood GLU and lipid levels in overweight and healthy subjects was analyzed. In addition, the correlation of CBC indices with TG, LDL, HDL, CHO and GLU was analyzed (Tables II and III). However, a limitation regarding the $\mathrm{CBC}$ indices is that there were may be multiple co-linear associations between these $\mathrm{CBC}$ indices.

For further analysis, MLR was used to evaluate the correlation of TG, LDL, HDL, CHO and GLU with CBC indices. MLR models the association between two or more explanatory variables and a response variable by fitting a linear equation (17). This differs from an artificial intelligence algorithm, which commonly requires complicated programming (18). MLR more easily provides regression models, which are linearly associated with their parameters.

The model summary (Table IV) demonstrated that the strongest correlation with the $\mathrm{CBC}$ indices was HDL, followed by TG, LDL, CHO and GLU, which was consistent with the 


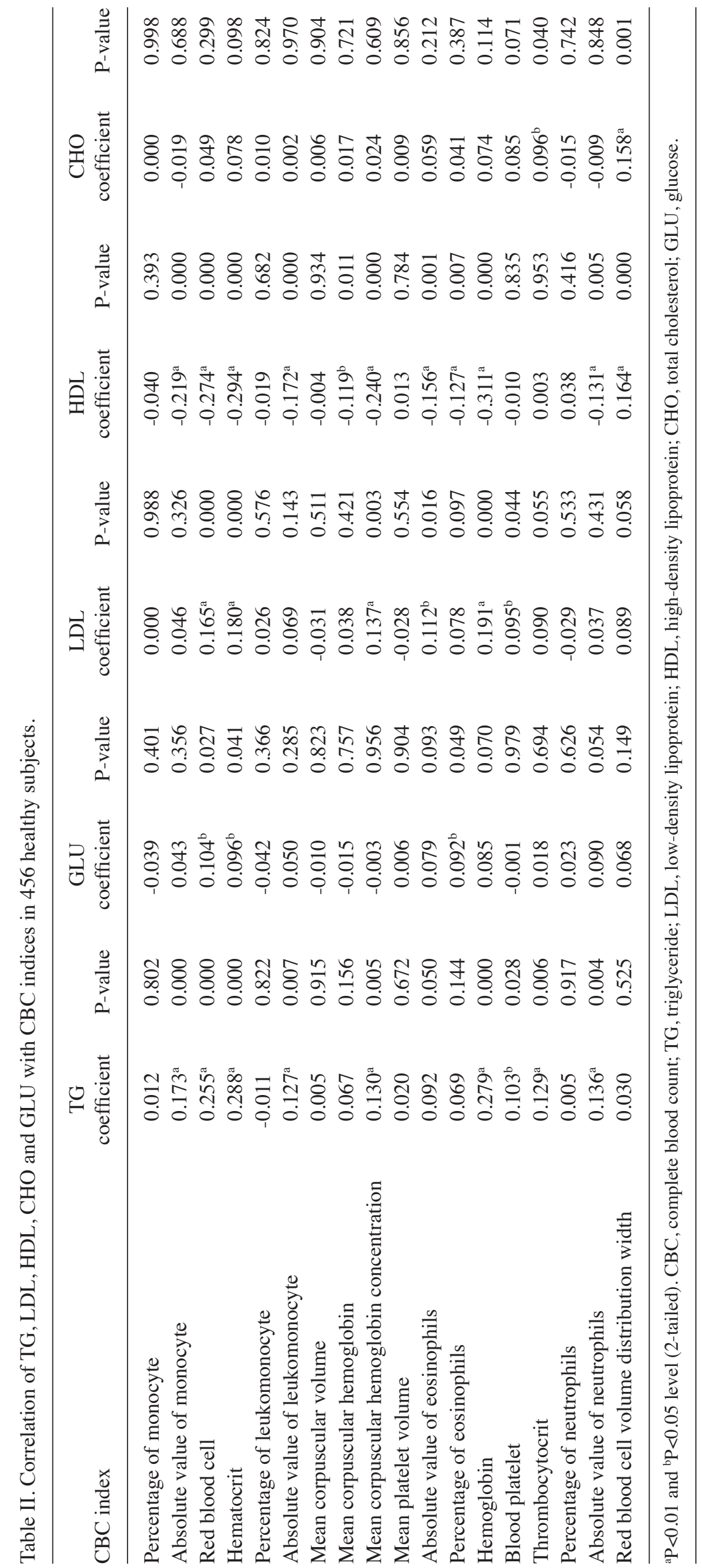




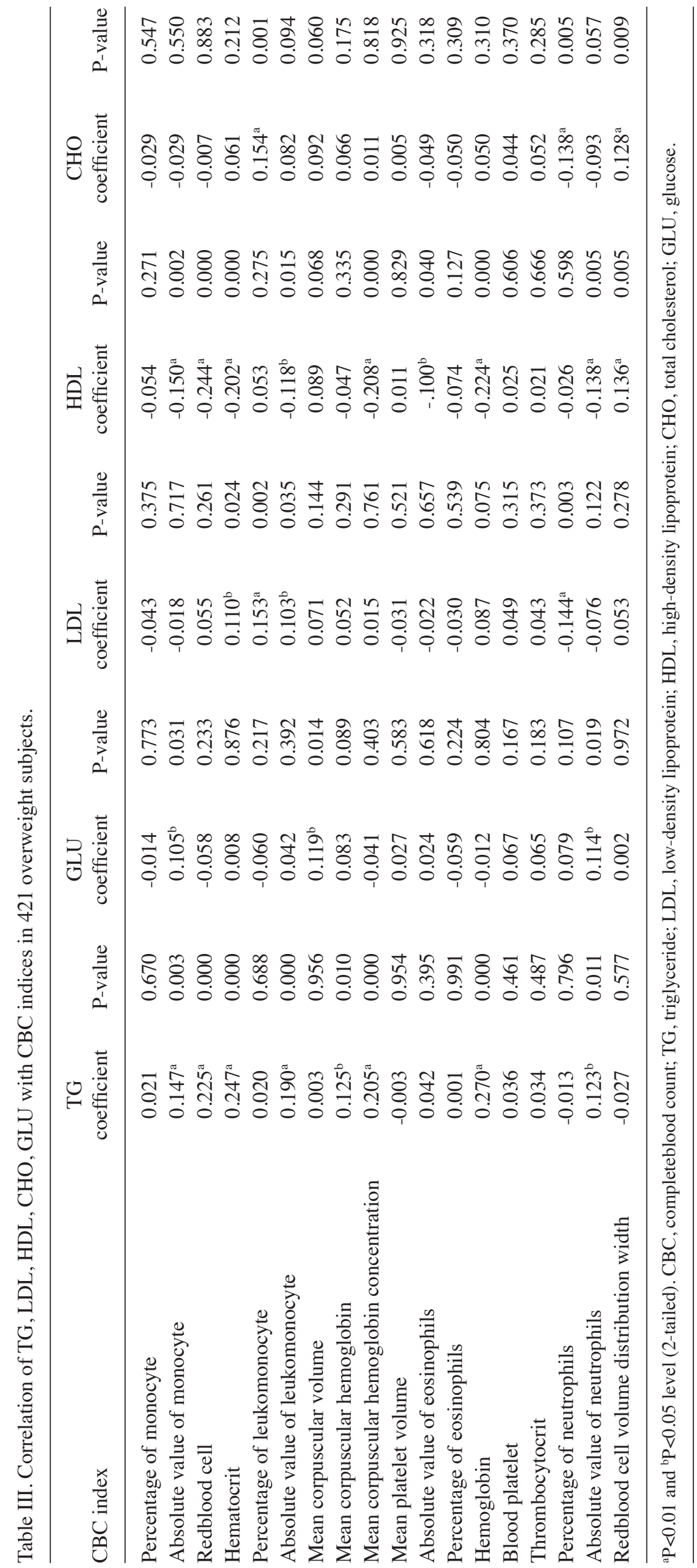


Table IV. Model summary of TG, LDL, HDL and CHO in healthy $(\mathrm{n}=456)$ and overweight $(\mathrm{n}=421)$ subjects.

\begin{tabular}{|c|c|c|c|c|c|c|c|}
\hline \multirow[b]{2}{*}{ Model } & \multirow[b]{2}{*}{ Index } & \multirow[b]{2}{*}{$\mathrm{R}$} & \multirow[b]{2}{*}{$\mathrm{R}^{2}$} & \multirow[b]{2}{*}{ Durbin-Watson } & \multirow[b]{2}{*}{ Predictors (constant) } & \multicolumn{2}{|c|}{ ANOVA } \\
\hline & & & & & & F-value & P-value \\
\hline \multirow[t]{4}{*}{ Healthy } & TG & 0.319 & 0.102 & 0.19 & HCT, PLT & 25.708 & 0.000 \\
\hline & LDL & 0.249 & 0.062 & 1.93 & HB, RBCVD, THR & 9.93 & 0.000 \\
\hline & HDL & 0.351 & 0.123 & 1.57 & HB, MPL, AVM & 21.18 & 0.000 \\
\hline & $\mathrm{CHO}$ & 0.232 & 0.054 & 1.9 & THR, RBCVD, MCH & 8.55 & 0.000 \\
\hline \multirow[t]{4}{*}{ Overweight } & TG & 0.189 & 0.036 & 1.93 & HB & 15.53 & 0.000 \\
\hline & LDL & 0.189 & 0.036 & 2.07 & PLC, HCT & 7.78 & 0.000 \\
\hline & HDL & 0.308 & 0.095 & 1.93 & RBC, RBCVD, AVM & 14.62 & 0.000 \\
\hline & $\mathrm{CHO}$ & 0.150 & 0.022 & 2.03 & PLC & 9.59 & 0.002 \\
\hline
\end{tabular}

TG, triglyceride; LDL, low-density lipoprotein; HDL, high-density lipoprotein; CHO, total cholesterol; R, correlation coefficient; R², determinate coefficient; HCT, hematocrit; PLT, blood platelet; HB, hemoglobin; RBCVD, red blood cell volume distribution; THR, thrombocytocrit; MPL, mean platelet volume; AVM, absolute value of monocyte; $\mathrm{MCH}$, mean corpuscular hemoglobin; PLC, percentage of leukomonocyte.

A

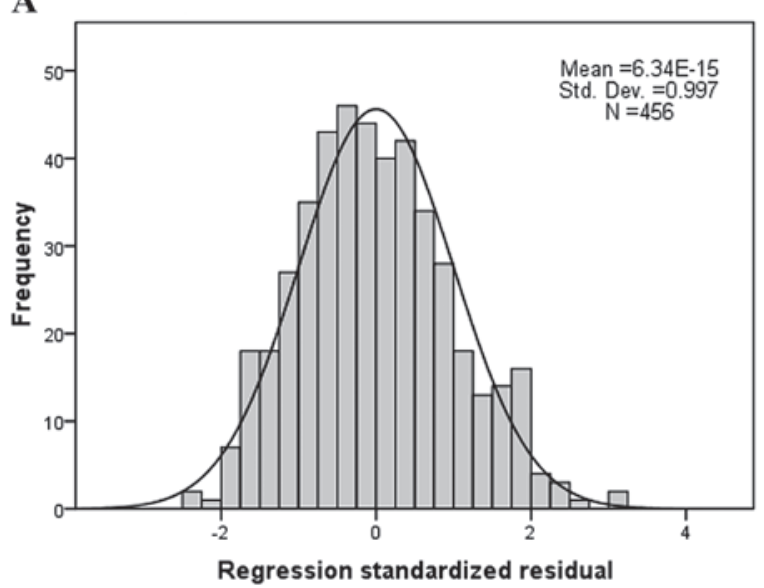

B

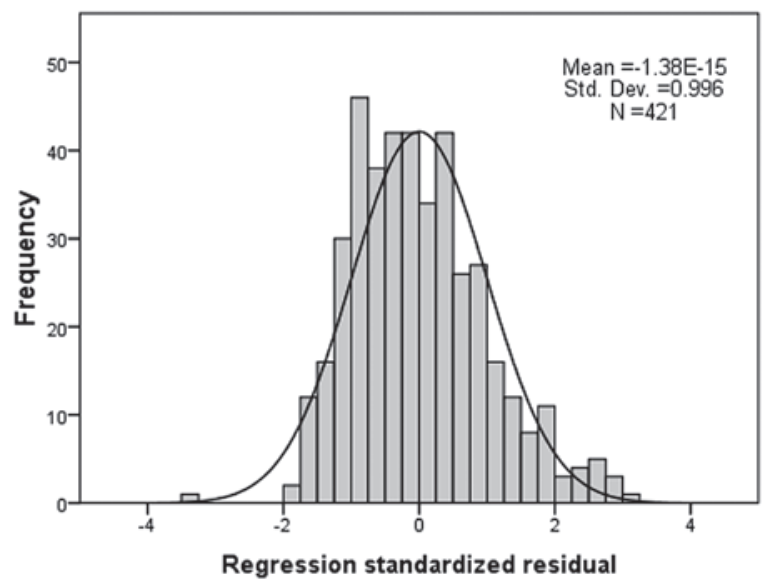

Figure 1. Histogram of regression standardized residuals (dependent variable, HDL) in (A) healthy and (B) overweight subjects. HDL, high-density lipoprotein.

results of the correlation analysis. However, almost the same associated CBC indices were identified between TG and HDL (Tables II and III). The multiple $\mathrm{R}$ and $\mathrm{R}^{2}$ were decreased markedly (Table IV). In addition, the regression standardized
A

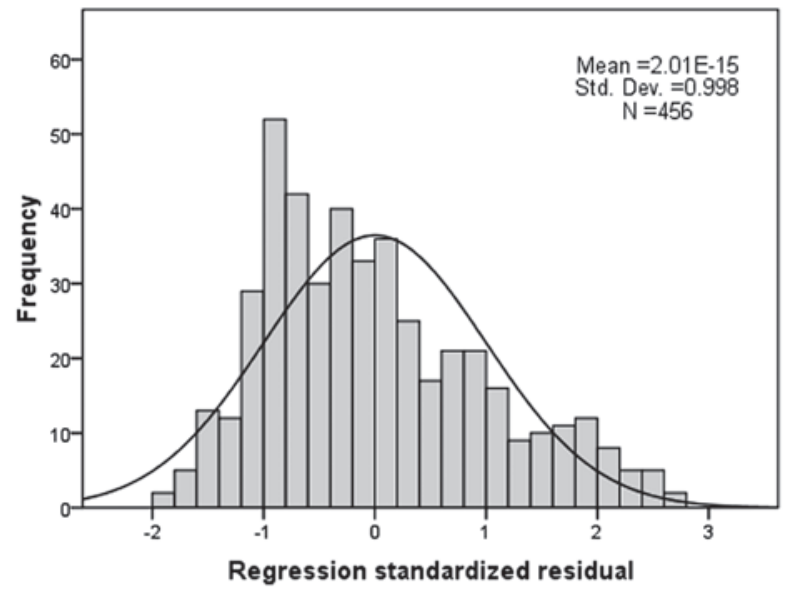

B

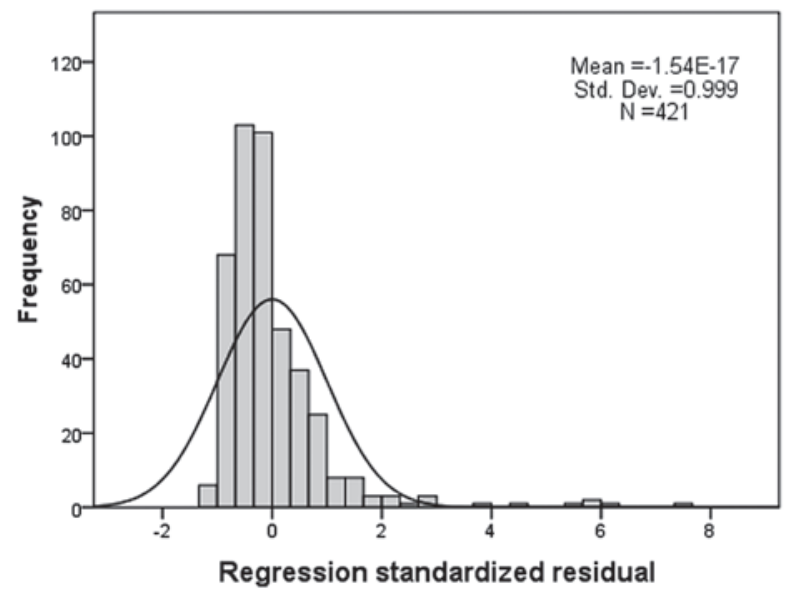

Figure 2. Histogram of regression standardized residuals (dependent variable, TG) in (A) healthy and (B) overweight subjects. TG, triglyceride.

residual was not normally distributed in TG, which indicates that TG is influenced by increasing weight, whereas HDL is not. Therefore, HDL is the most stable and correlated index within the $\mathrm{CBC}$ indices. According to the results of the present 
study, this prediction model may be developed in further studies, such as back-propagation artificial neural network (19) and extreme learning machine (10) models, and support vector machine (20) to improved predictive capabilities.

In conclusion, significant differences in GLU, lipid and $\mathrm{CBC}$ indices were observed between healthy and overweight subjects. The correlation and MLR analyses indicated that there were strong correlations between TG, LDL, HDL and $\mathrm{CHO}$, but not GLU, for which no linear regression model was generated. Among these indices, HDL was identified as the index that was most strongly correlated with the CBC indices. Thus, the CBC test is considered to be helpful in the diagnosis of hyperlipidemia.

\section{Acknowledgements}

The present study was supported by the National Science and Technology Major Project (grant no. 2012ZX10002004) and the Chinese High Tech Research \& Development (863) Program (grant no. 2013AA020102).

\section{References}

1. Guariguata L, Whiting DR, Hambleton I, Beagley J, Linnenkamp U and Shaw JE: Global estimates of diabetes prevalence for 2013 and projections for 2035. Diabetes Res Clin Pract 103: 137-149, 2014.

2. Khine AA and Marais DA: High prevalence of primary dyslipidaemia in black South African patients at a tertiary hospital in northern Gauteng, South Africa. S Afr Med J 106: 724-729, 2016.

3. Jameson K, Amber V, D'Oca K, Mills D, Giles A and Ambegaonkar B: Impact of lipid-lowering therapy on the prevalence of dyslipidaemia in patients at high-risk of cardiovascular events in UK primary care - a retrospective database study. Int J Clin Pract 67: 1228-1237, 2013.

4. Tran HA, Chua Y and Petrovsky N: Test and teach. Number Fifty-three. Diagnosis: Diabetes-related dyslipidaemia. Pathology 36: 576-579, 2004.

5. Agoșton-Coldea L, Zdrenghea D, Pop D, Crăciun A, Rusu ML and Mocan T: Prevalence and particularities of dyslipidaemia in subjects with coronary heart disease. Rom J Intern Med 45: 341-347, 2007.

6. Zhang L, Qiao Q, Laatikainen T, Söderberg S, Jousilahti P, Onat A, Nilsson P and Tuomilehto J; DECODE Study Group: The impact of dyslipidaemia on incidence of coronary heart disease in Finns and Swedes with different categories of glucose tolerance. Diabetes Res Clin Pract 91: 406-412, 2011.

7. Fiorentino TV, Prioletta A, Zuo P and Folli F: Hyperglycemia-induced oxidative stress and its role in diabetes mellitus related cardiovascular diseases. Curr Pharm Des 19: 5695-5703, 2013.
8. Teramoto T, Sasaki J, Ishibashi S, Birou S, Daida H, Dohi S, Egusa G, Hiro T, Hirobe K, Iida M, et al: Other types of primary hyperlipoproteinemia(hyperlipidemia). Executive summary of the Japan Atherosclerosis Society (JAS) guidelines for the diagnosis and prevention of atherosclerotic cardiovascular diseases in Japan - 2012 version. J Atheroscler Thromb 21: 82-85, 2014

9. Myers L and Mendis S: Cardiovascular disease research output in WHO priority areas between 2002 and 2011. J Epidemiol Glob Health 4: 23-28, 2014.

10. Chen H, Yang B, Liu D, Liu W, Liu Y, Zhang X and Hu L: Using blood indexes to predict overweight statuses: An extreme learning machine-based approach. PLoS One 10: e0143003, 2015.

11. Hartman ML, Goodson JM, Barake R, Alsmadi O, Al-Mutawa S, Ariga J, Soparkar P, Behbehani J, Behbehani K and Welty F: Salivary glucose concentration exhibits threshold kinetics in normal-weight, overweight, and obese children. Diabetes Metab Syndr Obes 8: 9-15, 2014.

12. Mateo-Gallego R, Perez-Calahorra S, Cofán M, Baila-Rueda L, Cenarro A, Ros E, Puzo J and Civeira F: Serum lipid responses to weight loss differ between overweight adults with familial hypercholesterolemia and those with familial combined hyperlipidemia. J Nutr 144: 1219-1226, 2014.

13. Di Bonito P, Pacifico L, Chiesa C, Invitti C, Miraglia Del Giudice E, Baroni MG, Moio N, Pellegrin MC, Tomat M, Licenziati MR, et al; 'CARdiometabolic risk factors in overweight and obese children in ITALY' (CARITALY) Study Group: White blood cell count may identify abnormal cardiometabolic phenotype and preclinical organ damage in overweight/obese children. Nutr Metab Cardiovasc Dis 26: 502-509, 2016.

14. No authors listed: Guidelines (2013) for managing overweight and obesity in adults. Preface to the Expert Panel Report (comprehensive version which includes systematic evidence review, evidence statements, and recommendations). Obesity (Silver Spring) 22 (Suppl 2): S40, 2014.

15. Li PF, Chen JS, Chang JB, Chang HW, Wu CZ, Chuang TJ, Huang CL, Pei D, Hsieh CH and Chen YL: Association of complete blood cell counts with metabolic syndrome in an elderly population. BMC Geriatr 16: 10, 2016.

16. Hassan U, Reddy B Jr, Damhorst G, Sonoiki O, Ghonge T, Yang $\mathrm{C}$ and Bashir R: A microfluidic biochip for complete blood cell counts at the point-of-care. Technology (Singap World Sci) 3: 201-213, 2015.

17. Wang J, Wang F, Liu Y, Xu J, Lin H, Jia B, Zuo W, Jiang Y, Hu L and Lin F; Multiple Linear Regression and Artificial Neural Network to Predict Blood Glucose in Overweight Patients: Multiple Linear Regression and Artificial Neural Network to Predict Blood Glucose in Overweight Patients. Exp Clin Endocrinol Diabetes 124: 34-38, 2016.

18. Hu L, Hong G, Ma J, Wang X, Lin G, Zhang X and Lu Z: Clearance rate and BP-ANN model in paraquat poisoned patients treated with hemoperfusion. Biomed Res Int 2015: 298253, 2015.

19. Ma J,Cai J,Lin G, Chen H, Wang X, Wang X and Hu L: Development of LC-MS determination method and back-propagation ANN pharmacokinetic model of corynoxeine in rat. J Chromatogr B Analyt Technol Biomed Life Sci 959: 10-15, 2014.

20. Wang X, Zhang M, Ma J, Zhang Y, Hong G, Sun F, Lin G and $\mathrm{Hu}$ L: Metabolic changes in paraquat poisoned patients and support vector machine model of discrimination. Biol Pharm Bull 38: 470-475, 2015. 